\section{Agricultural Development in the West Indies.}

THOSE interested in tropical agriculture will 1 find much worthy of attention in a paper on "Tropical Departments of Agriculture, with Special Reference to the West Indies," written by Sir Francis Watts, Imperial Commissioner of Agriculture for the West Indies, and published in the Journal of the Royal Society of Arts (February 20). The paper contains a very interesting account of the evolution of tropical Departments of Agriculture, pointing out that these Departments had their origin in the botanical gardens which were started in the larger islands in the eighteenth century, and also in the mission gardens which the early missionaries cultivated around their stations. The author traces the decline of the British West Indian sugar industry, and the efforts to revive it and to stimulate agriculture by the formation of botanical departments in the smaller islands. Economic conditions, however, became worse, and in 1896 the West Indian Royal Commission was appointed, and its report marks a period in West Indian history. As an outcome of this report the Imperial Department of Agriculture was constituted, the expense of which was met by Imperial funds. The policy of the Department was to revive, extend, and improve the already existing botanic gardens. This action so fostered agricultural development that, at the end of ten years, the Colonial finances had so improved that it was decided to diminish progressively the Imperial grants to the various stations, until in $1912-13$ these grants ceased. Sugar production is still a highly important industry; it has been very much improved; the pests and diseases of the sugar-cane are understood, and, what is more important, the growers know how to control the pests; also, the sugar produced by the factories is now a much more valuable product than the old muscovado sugar. The cacao and lime industries have been studied and improved; some minor industries, e.g. onion-growing, have also been studied to the advantage of the growers; while encouragement has been given to the production of such crops as maize for home consumption. The latter activity is especially important at the present time, when a wheat shortage is threatened.

\section{A Simple Viscometer.}

PARTICULARS of a remarkably simple viscometer devised by Mr. A. G. M. Michell, of Melbourne, are given in Engineering for April 16 . The instrument is intended for workshop use, and gives rapid determinations of viscosity in absolute measure without requiring extraordinary care or skill. It consists of a cup fitted with a handle and a ball of the same curvature as the cup. Contact of these surfaces is prevented by three symmetrically disposed projections in the cup, raised a mil or two above its surface. The cup is held by its handle, and a few drops of the oil to be tested are placed in it. The ball is then placed in the cup and pressed firmly into it for five or ten seconds. This drives some of the oil out, which collects in a channel; enough oil must be provided in the first instance to ensure that the channel is filled. The instrument is then inverted, and the time taken for the ball to drop clear noted. This time in seconds divided by the constant of the instrument is equal to the absolute viscosity of the oil. The action depends upon the rate at which the oil-film between the cup and the ball thickens under the force of gravity exerted by the ball. This flow of oil is resisted by its viscosity, and the time taken for the ball to fall clear is accordingly directly proportional to the viscosity. The above method is sufficiently accurate for workshop use. To obtain accurate results, the ball is placed at the bottom of a vessel containing a considerable quantity of the liquid. The cup is then lowered over the ball, taking care to exclude air. After pressing the two together as before, they are lifted until the ball clears the bottom of the vessel, and the time it takes to drop clear is noted as before. Mr. W. Ramsay, of Messrs. Cammell and Laird, has made as many as 120 most concordant readings in two hours, and the results plotted quite regularly. With liquids of very low viscosity, the ball is suspended from the arm of a balance. By adjusting the weights, the force tending to separate the ball from the cup can be diminished to, sav, onetwentieth of the normal. This increases twentyfold the time needed to effect the separation. The manufacture in this country has been undertaken by Messrs. Michell Bearings, Ltd., 3 Central Buildings, London, S.W.I.

\section{The Chemical Society and its New By-laws.}

$T$ is not surprising in these days, when the old political order has been challenged in so many quarters, that even the scientific societies should be moved to recast their constitution and government in a democratic sense. The Chemical Society is the latest to complete this process of revision, and a record of the chief points in which changes have been made is of public interest.

As a preliminary to any fundamental alterations, a supplemental charter was found to be necessary. The original charter of 1848 included many hampering restrictions, prescribing, for example, the maximum size of the council and the manner of its election. Such provisions, devised for the conduct of a small society associated mainly with London and the immediate districts, are quite unsuitable now that the society numbers more than 3500 fellows, and when probably about two-thirds of these reside beyond the metropolitan area.

There has been some doubt also whether, under the original charter, it was permissible to elect women as fellows of the society. Uncertainty on this point has now been removed by the supplemental charter, which provides that fellows may be of either sex.

Another important feature of the new by-laws based on the supplemental charter is the attempt to secure for provincial fellows a greater share in the conduct of the society. Hitherto every important matter affecting the society, including the election of officers and council, has been determined at a general meeting by a majority of the fellows present and voting. Under the supplemental charter the society has power to elect the officers and council by a postal vote, and further, in certain cases, to take a poll of all fellows resident in the United Kingdom. These powers have been incorporated in the new by-laws.

Another important aspect of these is that there has been kept in view the contingency of combined action with kindred societies concerned in the development of chemical science, as, for example, in the possible acquisition of common premises, or in the publication of joint abstracts. Under the new provisions there will be greater liberty to deal with such a situation if and when it arises, and it may be that these particular modifications of the by-laws will prove to be amongst the most important that have been made. No. 2637 , VOL. IO5] 